\title{
A Reduced Rate of In Vivo Dopamine Transporter Binding is Associated with Lower Relative Reinforcing Efficacy of Stimulants
}

\author{
Sunmee Wee', F Ivy Carroll ${ }^{2}$ and William L Woolverton*,I \\ 'Department of Psychiatry and Human Behavior, University of Mississippi Medical Center, Jackson, MS, USA; ${ }^{2}$ Center for Organic and Medicinal \\ Chemistry, Research Triangle Institute, Research Triangle Park, NC, USA
}

\begin{abstract}
A slow onset of action has been hypothesized to weaken the reinforcing effects of drugs. The present study evaluated this hypothesis with slow-onset cocaine analogs, WIN 35428, RTI 31, and RTI 5I. When cocaine or a cocaine analog was made available to rhesus monkeys ( $n=4$ or 5 ) for self-administration under a progressive-ratio (PR) schedule with a I-h time-out between injections, all the drugs functioned as positive reinforcers. The maximum number of injections was in the order of cocaine $>$ WIN $35428>R T I 3 I>R T I 5 I$. In in vivo binding in rat striatum, equipotent doses of cocaine, WIN 35428, RTI 31 , and RTI 5 I were estimated to displace $25 \%$ of $\left.{ }^{3} \mathrm{H}\right] \mathrm{WIN}$ 35428 binding at the dopamine transporters (DAT), respectively, 5.8, 22.4, 30.8, and 44.I min after the intravenous injection. Further, relative reinforcing efficacy was correlated with rate of DAT binding such that slower displacement of $\left.{ }^{3} \mathrm{H}\right] \mathrm{WIN} 35428$ was associated with a weaker reinforcing effect. In in vitro binding in monkey brain tissue, the cocaine analogs had higher affinity for monoamine transporter sites, but similar affinity ratios of 5-HTT/DAT, compared to cocaine. Lastly, RTI 3I was shown to function as a positive reinforcer in drug-naïve rhesus monkeys under a fixed-ratio I schedule. Collectively, the data support the hypothesis that a slow onset at the DAT is associated with reduced reinforcing efficacy of DAT ligands. The data under both the PR and FR schedules, however, suggest that a slow onset at the DAT influence reinforcing effect only to a limited extent.

Neuropsychopharmacology (2006) 31, 35I-362. doi: I0.1038/sj.npp. I300795; published online I5 June 2005
\end{abstract}

Keywords: dopamine; pharmacokinetics; rhesus monkey; self-administration; stimulants

\section{INTRODUCTION}

It is well established that cocaine can function as a positive reinforcer in humans and non-humans. The reinforcing effect of cocaine appears related to its action at the dopamine transporters (DAT) in the CNS. Drugs that inhibit the DAT, for instance, functioned as positive reinforcers (Bergman et al, 1989; Tella et al, 1997). Moreover, the potency of cocaine-like drugs in selfadministration was positively correlated with binding affinity at the DAT in vitro (Ritz et al, 1987; Bergman et al, 1989). Simple potency as a reinforcer, however, does not seem to predict abuse potential particularly well. Abuse has rather been more strongly associated with efficacy as a reinforcer (see Brady and Griffiths, 1976). Reinforcing efficacy, or reinforcing strength, here refers to the

\footnotetext{
*Correspondence: Dr WL Woolverton, Department of Psychiatry and Human Behavior, University of Mississippi Medical Center, 2500 North State Street, Jackson, MS 39216-4505, USA. Tel: + I 60I 984 5890, Fax: + | 601984 5899, E-mail: wwoolverton@psychiatry.umsmed.edu Received 3 March 2005; revised 6 May 2005; accepted 9 May 2005 Online publication: 10 May 2005 at http://www.acnp.org/citations/ NPP05 I 005050 | 49/default.pdf
}

maximum reinforcing effect. Cocaine, for example, has a relatively weak affinity at the DAT, and low potency as a reinforcer, but is one of the most efficacious reinforcers in laboratory animals and is highly abused by humans. This dissociation between potency and efficacy as a reinforcer can also be found in other DAT inhibitors (Roberts et al, 1999; Woolverton et al, 2001). Thus, pharmacological factors other than or in addition to DAT inhibition appear to determine reinforcing efficacy.

Cocaine penetrates the brain quickly after peripheral administration and produces a 'high' in less than a minute (Fowler et al, 1998; Volkow et al, 2000). This relatively rapid onset of action seems to contribute to cocaine's high efficacy as a reinforcer. Balster and Schuster (1973) demonstrated that decreasing the infusion rate of intravenous (i.v.) cocaine decreased responding maintained by cocaine in a manner similar to a decrease of a unit dose in rhesus monkeys under a fixed-interval schedule. Comparable results have been described under a fixed-ratio 30 schedule (Panlilio et al, 1998). When reinforcing efficacy was compared for i.v. cocaine with different injection duration under a progressive-ratio (PR) schedule, an increase of injection duration significantly diminished 
reinforcing efficacy as it significantly decreased rate of DAT occupancy (Woolverton and Wang, 2004). Data from humans are also consistent with the conclusion that rate of onset affects reinforcing effects. Using positron emission tomography, Volkow and colleagues (2000) suggested that the rate of cocaine delivery was a reliable predictor for the intensity of subjective effects.

The hypothesis that a slow onset is associated with reduced reinforcing efficacy has been tested to a limited extent across DAT ligands. In two-drug comparisons, diminished reinforcing efficacy of a piperidine analog (Woolverton et al, 2002) or a tropane analog (Lile et al, 2002) relative to cocaine was attributed to its slower rate of onset. On the other hand, in a comparison across several drugs, no obvious relationship between rate of onset and reinforcing efficacy was observed (Lile et al, 2003). Therefore, the relationship between onset of action and reinforcing efficacy across DAT ligands remains equivocal. The present study was designed to further investigate the relationship between reinforcing efficacy and onset at the DAT across DAT ligands within a single chemical class (phenyltropanes). Reinforcing efficacy was measured using the maximum number of injections that a drug maintained under a PR schedule. This dependent measure has been shown to be comparable to the more traditional break point measure, and more amenable to statistical analysis (see Rowlett et al, 1996).

\section{MATERIALS AND METHODS}

All animal use procedures were approved by the University of Mississippi Medical Center's Animal Care and Use Committee and were in accordance with National Institutes of Health guidelines.

\section{Self-Administration by Experienced Monkeys}

Animals and apparatus. The subjects were five male rhesus monkeys (Macaca mulatta), L638, Rik2, AV88, L463, and L500, weighing between 9.9 . and $11.5 \mathrm{~kg}$ at the beginning of the study. All the monkeys had histories of self-administration of cocaine and/or other stimulants. All monkeys were provided with sufficient food to maintain stable body weight (Teklad 25\% Monkey Diet, Herlan/Teklad, Madison, WI) and had unlimited access to water. Fresh fruit was provided daily and a vitamin supplement was given three times a week. Lighting in the experimental room was cycled to maintain $21 \mathrm{~h}$ of light and $3 \mathrm{~h}$ of dark, with light on at $0700 \mathrm{~h}$ and off at $0400 \mathrm{~h}$ during the study. The monkeys were fit with restraint harnesses and tethers, and individually housed in the experimental cubicles equipped with response levers, stimulus lights, and infusion pumps, as described previously (see Wilcox et al, 2000). A Macintosh computer with custom interface and software controlled all events in an experimental session.

Procedure. Monkeys were anesthetized using ketamine and isoflurane and implanted with a silicone catheter $(0.26 \mathrm{~cm}$ o.d. $\times 0.076 \mathrm{~cm}$ i.d.; Cole-Parmer Co., Chicago, IL) in the jugular (internal or external) or femoral vein. The proximal end of the catheter was inserted into the vein and terminated in the vena cava near the right atrium. The distal end was threaded subcutaneously to the back of the monkey where it exited through a small opening in the skin. The catheter was threaded through the tether, exited through the rear of the cubicle and connected to the peristaltic pump. Experimental sessions began at $1000 \mathrm{~h}$ each day and were conducted 7 days per week. At $30 \mathrm{~min}$ before each session started, catheters were filled with drugs for the sessions without infusing the drugs into monkeys. At the start of a session, the white lights were illuminated above both levers and responding on the right lever resulted in the delivery of a drug injection via the catheter for $10 \mathrm{~s}$. During the injection, the white lights were extinguished and the red lights were illuminated. Pressing the left lever was counted but had no other programmed consequence.

Drugs were available under a PR schedule of reinforcement (see Wilcox et al, 2000). The PR schedule consisted of five components, four trials in each component, for a total of 20 trials/day. For four monkeys, the response requirement began at 200 responses/injection and doubled in each successive component. For monkey L638, responding was not well maintained under the PR 200, so the initial response requirement was reduced to a 50 and doubled in each successive component. A subject had $30 \mathrm{~min}$ to complete a trial (limited hold $30 \mathrm{~min}$ : LH $30 \mathrm{~min}$ ). A trial ended with a 10-s drug injection or the expiration of the LH. It was rare that the $\mathrm{LH}$ interrupted completion of the response requirement under this $P R$ schedule since the pattern of responding was mostly all or none in each trial in all monkeys. There was a $60 \mathrm{~min}$ time-out (TO $60 \mathrm{~min}$ ) after each trial. If the response requirement was not completed for two consecutive trials (ie the $\mathrm{LH}$ expired), or the animal self-administered all 20 injections, the session ended.

In baseline sessions, cocaine or saline was available for an injection. The baseline dose $(0.3 \mathrm{mg} / \mathrm{kg} /$ injection $)$ of cocaine was available until responding was stable for three consecutive sessions (mean \pm 2 injections/session with no trends). Saline was then available daily until responding declined to $<5$ injections/session. Cocaine baseline was then re-established and, when stable, doses of cocaine or other test drugs were available for at least the number of sessions required for saline-maintained responding to decline and until responding was stable for three consecutive sessions (mean \pm 2 injections with no trend). The data from the last three sessions of stable responding were used for data analysis. After testing a dose of a drug, baseline sessions with cocaine and saline were inserted to assure the stability of responding. Cocaine $(0.01-1.0 \mathrm{mg} / \mathrm{kg} /$ injection) was tested in consecutive daily sessions. However, because of evidence that responding maintained by the highest dose $(0.03 \mathrm{mg} / \mathrm{kg})$ of RTI 31 in one session affected responding in the session on the following day in monkeys L463, Rik2, and AV88, test sessions were conducted every other day for RTI 31 (0.0003-0.03 mg/kg/injection), WIN 35428 (0.001-0.3 mg/kg/injection), and RTI 51 (0.001$0.1 \mathrm{mg} / \mathrm{kg} /$ injection), with no session on intervening days. The drugs were tested in the order cocaine, RTI 31, WIN 35428 , and RTI 51, with doses of each drug tested in a random order. The effect of high doses of cocaine was redetermined at the end of the study. All the compounds except RTI 51 were tested in five monkeys. RTI 51 was examined in four monkeys because monkey L638 lost its final catheter during the study. 
Data analysis. The mean number of injections/session was calculated from the last three test sessions as a function of dose. The range of injections served as a measure of variability in individual subjects. A dose was considered to function as a reinforcer in a monkey if the mean number of injections was above saline levels and the ranges did not overlap. Log $\mathrm{ED}_{50}$ values were calculated in individual monkeys over the ascending portion of the dose-response function using nonlinear regression analysis (GraphPad Prism 3.0). Mean $\mathrm{ED}_{50}$ 's were calculated for each drug by averaging these log values and taking the antilog. Relative potency was compared with $\mathrm{ED}_{50}$ values using one-way repeated measures analysis of variance (ANOVA). The mean total intake/session was also calculated from the last three test sessions as a function of dose by multiplying the number of injections/session by the dose and by averaging them from the last three sessions.

For a group dose-response function for each drug, the mean number of injections per session was averaged as a function of dose across the four out of five monkeys because the drugs in the fifth monkey (L638) were tested under a different condition from the other monkeys. However, for statistical analysis to compare maximum responding across the drugs, normalized group dose-response functions for the drugs were obtained so that the fifth monkey (L638) was included. The number of injections was first normalized to the percentage of the maximum cocaine injections in each monkey. The normalized maximum responding for each drug in individual monkeys were, then, averaged across the monkeys as to the dose of the maximum responding, regardless of the absolute values of the doses. This was carried out because each drug maintained qualitatively comparable dose-response functions across monkeys but with the maximum responding seen at a different doses across subjects (see, Woolverton and Wang, 2004). Repeated one-way ANOVA with Student-Newman-Keul as a post hoc test was conducted on these normalized data to assess statistically significant differences among drugs in the maximum self-administration. Statistical analysis of RTI 51 in comparison to the rest of the drug was conducted on the data of four monkeys without monkey L638.

\section{Acquisition of Self-Administration By Naïve Monkeys}

Animals and apparatus. The subjects were four male rhesus monkeys (M. mulatta; M1389, 96R0661, 97R0111, and 96R0679). All the monkeys except M1389 were drug naïve at the beginning of the study. Monkey M1389 had been trained to respond under variable-ratio schedule of food reinforcement for 14 sessions and had self-administered cocaine in one session. Other aspects of animals and apparatus were the same as described for experienced monkeys.

Procedure. The acquisition of drug self-administration was tested under a fixed-ratio 1 (FR1) schedule. That is, pressing the active lever once resulted in a drug delivery. For all naive monkeys, the right lever was active and the left lever inactive. Owing to his brief experience pressing the right lever, this arrangement was reversed in monkey M1389. Saline or RTI 31 were made available in successive sessions until responding was stable (the range of injections/session over three consecutive sessions is within $\pm 20 \%$ of the mean or \pm 4 injections of the mean when the number of injections was less than 10). RTI 31 was selected for this experiment because of its slow rate of in vivo DAT binding and because it was readily available. Sessions began at noon each day, 7 days per week, and lasted for $4 \mathrm{~h}$.

At the beginning of the study, saline was made available. When a monkey did not press levers for $1 \mathrm{~h}$ in the first session, a raisin or other piece of fruit was taped on the active lever every half an hour. Otherwise, no bait was used. Beginning with session two, no bait was taped on an active lever for the first half-hour. When the monkey did not initiate responding, baiting was repeated every half-hour over the session. The baiting procedure was used for a maximum of five sessions. Subsequent sessions were without bait for at least three sessions and until responding was stable. After saline sessions, $0.0015 \mathrm{mg} / \mathrm{kg} /$ injection of RTI 31 was available at least for the same number of sessions, and using the same protocol, as and when saline was available. If the dose of RTI 31 reliably maintained responding above saline level, the dose of RTI 31 was reduced to $0.0003 \mathrm{mg} / \mathrm{kg} /$ injection. After testing these two doses of RTI 31, saline was again substituted for RTI 31 until responding declined. If responding above saline levels was not established using $0.0015 \mathrm{mg} / \mathrm{kg} /$ injection of RTI 31, a higher dose $(0.01 \mathrm{mg} / \mathrm{kg})$ of RTI 31 was made available using the same protocol. After testing $0.01 \mathrm{mg} / \mathrm{kg}$ of RTI 31, $0.0015 \mathrm{mg} / \mathrm{kg} /$ injection of RTI 31 was retested and then $0.0003 \mathrm{mg} / \mathrm{kg}$ were tested.

Data analysis. The mean injections/session and total intake/session were calculated for individual monkeys from the last three test sessions. The range of injections served as a measure of variability in individual subjects. A dose of a drug was considered to function as a reinforcer if the mean injections/session was above levels seen with saline and the ranges did not overlap.

\section{In Vivo Binding}

The method for in vivo binding studies has been described previously (Stathis et al, 1995; Woolverton et al, 2002).

Animals and apparatus. Male Sprague-Dawley rats, weighing between 250 and $300 \mathrm{~g}$, were initially housed in groups of three in standard plastic rodent cages under a $12: 12$ light: dark cycle (lights on at $0600 \mathrm{~h}$ ). Food and water were available ad libitum.

Procedure. Rats were surgically implanted with polyethylene catheters (PE 10; $0.28 \mathrm{~mm}$ i.d. $\times 0.61 \mathrm{~mm}$ o.d.; Becton Dickinson \& Co.) into femoral veins under pentobarbital ( $50 \mathrm{mg} / \mathrm{kg}$, intraperiotoneally) anesthesia. The distal end of the catheter was threaded subcutaneously to exit the rat between the scapulae, flushed with heparin $(20 \mathrm{IU} / \mathrm{ml})$, and sealed by heat. After surgery, rats were individually housed at least for 2 days, and then used experimentally.

Binding at the DAT was studied for each drug in vivo via competition studies using $\left[{ }^{3} \mathrm{H}\right]$ WIN 35428 as the DAT radioligand. The pretreatment time between injection of a test drug and injection of $\left[{ }^{3} \mathrm{H}\right]$ WIN 35428 was first 
determined for RTI 31, WIN 35428, and RTI 51. Catheterized rats were placed in a plastic restrainer. After establishing the patency of the catheter by flushing saline, a selected dose of each drug was injected via the catheter in an injection volume of $1.0 \mathrm{ml} / \mathrm{kg}$ delivered over $10 \mathrm{~s}$ and flushed with saline. The dose was selected based on $\mathrm{ED}_{50}$ doses of in vivo binding in mice in a previous study (Scheffel et al, 1991). Between 5 and 30 min after a test drug injection, $\left[{ }^{3} \mathrm{H}\right]$ WIN $35428(10 \mu \mathrm{Ci} / 0.4 \mathrm{ml} / \mathrm{rat})$ was injected. The rat was returned to a cage until killed by decapitation 45 min after $\left[{ }^{3} \mathrm{H}\right]$ WIN 35428 injection, the time at which specific $\left[{ }^{3} \mathrm{H}\right]$ WIN 35428 binding has been found to be asymptotic (Scheffel et al, 1991). Brains were immediately removed and the striatum (about $60 \mathrm{mg}$; high DAT density) and cerebellum (about $190 \mathrm{mg}$; nonspecific binding) were dissected (Kaufman and Madras, 1992). Tissue samples were weighed, placed into glass vials, and solubilized in Solvable $^{\mathrm{TM}}$ (10 $\mu \mathrm{l} / \mathrm{mg}$ tissue; Perkin-Elmer, Boston, MA) overnight. After solubilization, glacial acetic acid $(1 \mu \mathrm{l} / \mathrm{mg}$ tissue) was added to neutralize Solvable ${ }^{\mathrm{TM}}$ and $200 \mu \mathrm{l}$ aliquots were placed in 24-well scintillation plates. Microscint-20 $0^{\mathrm{TM}}$ cocktail (Packard Instruments, Downers Grove, IL) was then added to each well and the preparation was allowed to sit at least $4 \mathrm{~h}$ to reduce chemiluminescence. Radioactivity was then counted using Packard Top Count ${ }^{\mathrm{TM}}$ scintillation counter (Downers Grove, IL). The time point at which the dose of a drug maximally inhibited the radioligand binding at the DAT was used as a pretreatment time to establish the dose-response function of each drug. For dose-response analysis, procedures were the same as above, except that various doses of a test drug were injected and $\left[{ }^{3} \mathrm{H}\right]$ WIN 35428 was injected after the defined pretreatment time for the test drug. An $\mathrm{ED}_{50}$ for the inhibition of $\left[{ }^{3} \mathrm{H}\right]$ WIN 35428 binding at the DAT was calculated as described below.

To study the kinetics of in vivo DAT binding for a drug, $\left[{ }^{3} \mathrm{H}\right]$ WIN $35428(10 \mu \mathrm{Ci} / 0.4 \mathrm{ml} / \mathrm{rat})$ was first injected to occupy the DAT and the $\mathrm{ED}_{50}$ dose of a test drug was injected $45 \mathrm{~min}$ after the radioligand injection. The $\mathrm{ED}_{50}$ dose was used to allow a comparison across drugs at functionally equivalent doses. At various time points after the test drug injection, rats were killed and the specific binding of $\left[{ }^{3} \mathrm{H}\right]$ WIN 35428 was measured. A study with saline was conducted in tandem at the same time points.

Data analysis. The binding ratio of $\left[{ }^{3} \mathrm{H}\right]$ WIN 35428 in the striatum and cerebellum (S/C) was calculated. When the binding ratio reached 1 , it was considered that the drug completely displaced the specific binding of $\left[{ }^{3} \mathrm{H}\right]$ WIN 35428 to the DAT in the striatum. In dose-response functions, the ratio data were transformed to the percentage of saline data and analyzed using nonlinear regression analysis assuming a one-site interaction (Prism 3.0, GraphPad, San Diego, CA). The dose that inhibited one-half of $\left[{ }^{3} \mathrm{H}\right]$ WIN 35428 binding was expressed as the $\mathrm{ED}_{50}$.

In the kinetic study, the displacement of $\left[{ }^{3} \mathrm{H}\right]$ WIN 35428 binding by the $\mathrm{ED}_{50}$ dose of a test drug was expressed as the percentage of $\left[{ }^{3} \mathrm{H}\right]$ WIN 35428 binding after saline treatment of the same time point as a function of time. Data were transformed to log values to fit the displacement curves to straight lines. As WIN 35428, RTI 31, and RTI 51 showed delay in displacing $\left[{ }^{3} \mathrm{H}\right]$ WIN 35428 binding at the DAT, a linear regression line in the displacement of $\left[{ }^{3} \mathrm{H}\right]$ WIN 35428 was obtained for each drug from the latest time point when the $\left[{ }^{3} \mathrm{H}\right]$ WIN 35428 binding was not reduced below $100 \%$ of the control binding (ie mean + SEM $\geqslant 100$ ) to the time point of the maximum displacement of $\left[{ }^{3} \mathrm{H}\right]$ WIN 35428 binding (Prism 3.0, GraphPad, San Diego, CA). To compare onsets of the drugs at the DAT, the time when $25 \%\left(T_{25}\right)$ and $50 \%\left(T_{50}\right)$ of $\left[{ }^{3} \mathrm{H}\right]$ WIN 35428 binding had been displaced were estimated and compared across drugs. The time point for $25 \%$ of the DAT binding was used because cocaine showed $25 \%$ of the displacement of the radioligand binding $2 \mathrm{~min}$ after the i.v. injection, a time that appears particularly relevant to the reinforcing effect (Volkow et al, 2000; Woolverton et al, 2002). The time point of $50 \%$ of the DAT binding was chosen because it was the maximum binding achieved by an $\mathrm{ED}_{50}$ dose. The correlation between the maximum responding under the $\mathrm{PR}$ schedule and the $T_{25}$, the $T_{50}$, or the slopes for the linear regression lines was obtained using the Pearson product-moment correlation (Prism 3.0, GraphPad, San Diego, CA). The differences among the slopes for the linear regression lines were analyzed using analysis of covariance with Bonferroni as a post hoc test (SPSS, SPSS Inc., Chicago, IL).

\section{In Vitro Binding}

Animals and apparatus. Brain tissues for rhesus monkeys (M. mulatta; caudate/putamen for the DAT; cerebellum for the NET; frontal cortex for the 5-HTT) were used. Each monkey had a history of drug self-administration and was drug free for at least 2 months before being killed. During that period, they were housed in stainless-steel primate cages with food and water available ad libitum. Monkeys were not killed specifically for the purposes of this experiment but as part of a general program to bank monkey brain tissue.

Procedure. Euthanasia and dissection were performed under veterinary supervision as described previously (Wee et al, 2004). In brief, monkeys were euthanized by an overdose of i.v. pentobarbital. Brains were collected and dissected immediately after killing and kept in an $80^{\circ} \mathrm{C}$ freezer until assay. On the day of binding study, frozen tissue was thawed, homogenized in Tris buffer $(50 \mathrm{mM}$, $\mathrm{pH}$ 7.4), and centrifuged at $20000 \mathrm{~g}$ for $20 \mathrm{~min}$ at $4^{\circ} \mathrm{C}$. The resulting pellet was collected. The washing procedure was repeated two or three times, depending on the assay. After centrifugation, the pellet was suspended in an incubation buffer at the appropriate tissue concentration.

Assay conditions were as published previously (Woolverton et al, 2002). The displacement of the radioligand binding (DAT: $\left[{ }^{3} \mathrm{H}\right]$ WIN 35428; NET: $\left[{ }^{3} \mathrm{H}\right]$ nisoxetine; 5HTT: $\left[{ }^{3} \mathrm{H}\right]$ paroxetine) was performed with various concentrations of cocaine, RTI 31, WIN 35428, and RTI 51. Concentrations ranged from one too low to displace the radioligand, to a concentration that maximally inhibited the radioligand binding, with at least 12 test concentrations. Nonspecific binding was measured in the presence of $10 \mu \mathrm{M}$ cocaine, $1 \mu \mathrm{M}$ mazindol, and $1 \mu \mathrm{M}$ sertraline for the DAT, NET, and 5-HTT transporters, respectively. All assays were initiated with the addition of tissue. Reactions ( $2 \mathrm{~h}$ for the 
DAT; $4 \mathrm{~h}$ for the NET; $1 \mathrm{~h}$ for the 5 -HTT) were terminated by rapid vacuum filtration. The collected membranes on the filters were rinsed with an ice-cold buffer and deposited into Packard Top Count ${ }^{\mathrm{TM}}$ deep well plates. Microscint-20 ${ }^{\mathrm{TM}}$ cocktail (Packard Instruments, Downers Grove, IL) was added to each well and allowed to stand overnight. Radioactivity was determined using a Packard Top Count ${ }^{\mathrm{TM}}$ scintillation counter.

Data analysis. Data were analyzed by competition using nonlinear regression analysis (Prism 3.0, GraphPad, San Diego, CA). Data were fit to models assuming a one-site interaction and two sites of interaction. The best of fit was determined by comparing the sum of squares of residuals using the following equation: $F=\left(\left(\mathrm{SS}_{1}-\mathrm{SS}_{2}\right) /\left(\mathrm{df}_{1}-\mathrm{df}_{2}\right)\right) /\left(\mathrm{SS}_{2} /\right.$ $\mathrm{df}_{2}$ ), where $\mathrm{SS}_{1}$ and $\mathrm{df}_{1}$ are the sum of squares and degrees of freedom from a one-site model and $\mathrm{SS}_{2}$ and $\mathrm{df}_{2}$ are that from a two-site model. A two-site model was considered a significantly better fit if the $\mathrm{F}$ value was greater than that reported in the F-statistic table at $p<0.05$ for the numerator of $\mathrm{df}_{1}-\mathrm{df}_{2}$ and the denominator of $\mathrm{df}_{2}$. $K_{\mathrm{i}}$ values were calculated from $\mathrm{IC}_{50}$ values using the Cheng-Prusoff correction factor (Cheng and Prusoff, 1973).

The correlation between reinforcing potencies and in vitro binding affinities at the DAT, NET, 5-HTT, 5-HTT/ DAT, or NET/DAT was measured using the Pearson product-moment correlation. The correlation between binding potencies in vivo and in vitro at the DAT was also conducted using the Pearson product-moment correlation. The correlation between reinforcing efficacy and in vitro binding affinities at the DAT, NET, 5-HTT, 5-HTT/DAT, or NET/DAT was also measured using the Pearson productmoment correlation. Correlation was performed on log- or square root-transformed data when the data violated the assumptions (ie equal variance, normal distribution, etc) for parametric analysis.

\section{Drugs}

Cocaine hydrochloride was provided by the National Institute on Drug Abuse (Rockville, MD). RTI 31 tartrate (3 $\beta$-(4-chlorophenyl)tropane- $2 \beta$-carboxylic acid methyl esters), WIN 35428 tartrate (3 $\beta$-(4-fluorophenyl)tropane$2 \beta$-carboxylic acid methyl esters), and RTI 51 tartrate $(3 \beta$ (4-bromophenyl)tropane- $2 \beta$-carboxylic acid methyl esters) were synthesized as reported previously (Carroll et al, 1991; Figure 1). Pentobarbital, mazindol, and sertraline were purchased from Sigma (St Louis, MO). For the selfadministration study, drugs were dissolved in $0.9 \%$ saline. Doses were expressed as the salt forms of the drugs. Radioligands $\left[{ }^{3} \mathrm{H}\right]$ WIN 35428, $\left[{ }^{3} \mathrm{H}\right]$ paroxetine, and $\left[{ }^{3} \mathrm{H}\right] \mathrm{ni}$ soxetine were purchased from Perkin-Elmer (Boston, MA). For in vitro binding and in vivo binding studies, drugs were freshly prepared for each experiment.

\section{RESULTS}

\section{Self-Administration by Experienced Monkeys}

Cocaine, RTI 31, WIN 35428, and RTI 51 functioned as positive reinforcers (Figure 2). Group mean dose-response functions were biphasic, while dose-response functions in

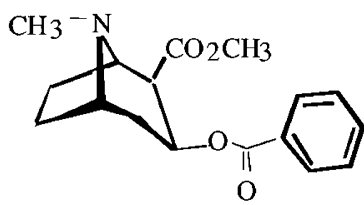

Cocaine

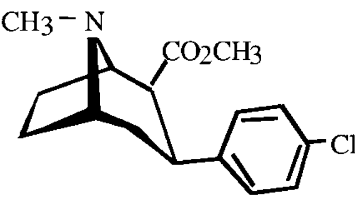

RTI 31

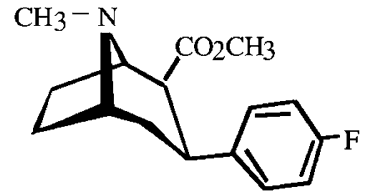

WIN 35,428

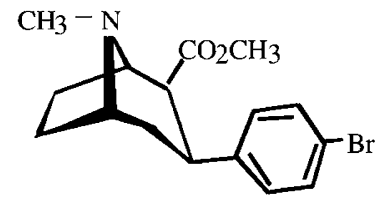

RTI 51
Figure I Chemical structures of cocaine and the phenyltropane analogs that were tested.

individual monkeys (not shown) were biphasic or sigmoidal. The dose that maintained the maximum number of injections differed by one-half log unit across the monkeys for each drug. Monkey L638 did not self-administer RTI 31 ( $\leqslant 3$ injections) when the initial response requirement for the PR was 200 but, when it was reduced to 50 in that monkey, RTI 31 maintained responding marginally above saline level at $0.01 \mathrm{mg} / \mathrm{kg} /$ injection. The $\mathrm{ED}_{50}$ values of the compounds were statistically different and the order of potency was RTI $31>$ RTI $51>$ WIN $35428 \gg$ cocaine (Table 1). In a group mean comparison (Figure 2), the rank order of the maximum self-administration was cocaine $>$ WIN 35428> RTI $31>$ RTI 51. Cocaine maintained significantly higher number of injections than any other compound and WIN 35428 maintained significantly higher number of injections than RTI 51. Intake of all the drugs dose dependently increased to the maximum (group mean; cocaine, $11.6 \mathrm{mg} / \mathrm{kg} / \mathrm{session}$; WIN 35428, $2.1 \mathrm{mg} / \mathrm{kg} / \mathrm{session;}$ RTI 51, 0.27 mg/kg/session; RTI 31, $0.17 \mathrm{mg} / \mathrm{kg} / \mathrm{session).}$

\section{Acquisition of Self-Administration by Drug-Naïve Monkeys}

In the acquisition study, two (M1389, 96R0661) of four monkeys pressed a lever at low rates when saline was initially made available (Figure 3, open circles). Monkeys 97R0111 and 96R0679, however, did not press a lever; therefore, the baiting procedure was used for the first five sessions. Monkeys took a mean of between 0.7 (96R0679) and 12.7 (M1389) injections/session over the last three sessions of saline availability (Figure 3). When $0.0015 \mathrm{mg} /$ $\mathrm{kg} /$ injection of RTI 31 was substituted for saline, monkeys M1389 and 96R0661 self-administered RTI 31 for an average of 18.3 and 21.3 injections/session, respectively. Further, the responses on the inactive lever in those two monkeys diminished from 5 (96R0661) or 84.7 (M1389) to 2.3 and 2 injections/session, respectively, during this period. The selfadministration of RTI 31 by those two monkeys increased to an average of 75.3 (96R0661) and 84.7 (M1389) injections/ session when the dose of RTI 31 was reduced to $0.0003 \mathrm{mg} /$ $\mathrm{kg} /$ injection. Total intake/session of RTI 31 was similar across doses. Monkey M1389 self-administered 0.032 and 


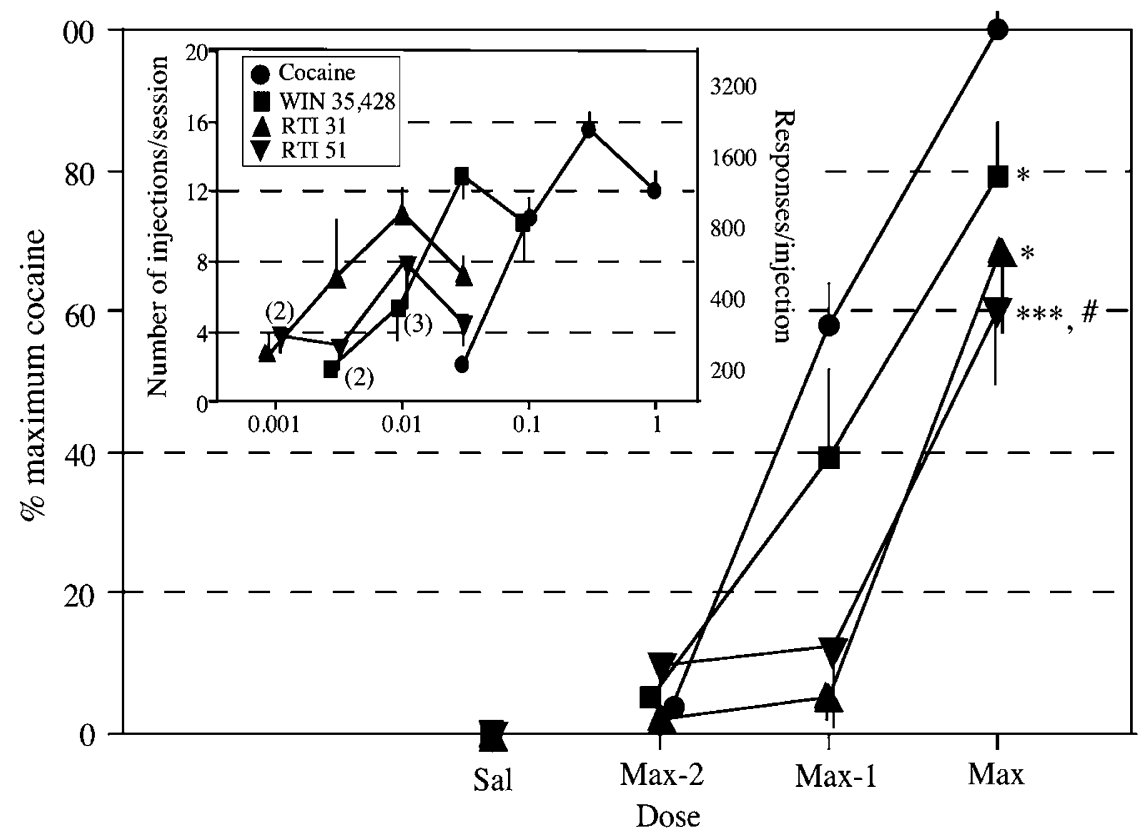

Figure 2 Self-administration of cocaine, WIN 35428, RTI 5I, and RTI 31 under a PR schedule of reinforcement. Injections/session of each drug were normalized to the percentage of the maximum cocaine injections in each monkey and collapsed across the monkeys as to a dose that maintained the maximum injections ( $n=5$ or 4 for RTI $5 \mathrm{I}$ ). Vertical bars indicate SEM values. $* * * * 2<0.00$ I compared with cocaine. $* 2<0.05$ compared with cocaine ${ }^{\#} p<0.05$ compared with WIN 35428. Sal: saline; Max: the dose that maintained the maximum injections in each animal; Max-I: a half-log lower dose than Max; Max-2: a half-log lower dose than Max-I. Inset: Dose-response functions of cocaine, WIN 35428, RTI 5I, and RTI 3 I in four monkeys under a PR schedule. Since the fifth monkey was tested under a different PR schedule, the data in that monkey were not included. The drugs were tested in different dose ranges in monkeys because of different sensitivities to the drugs. Thus, data points are the mean of four or less monkeys. When the data point was pooled from less than four monkeys, the number of subjects is indicated in parenthesis.

Table I Potency Comparisons among the Drugs in Self-Administration under a PR Schedule of Reinforcement and in Dopamine Transporter Binding

\begin{tabular}{|c|c|c|c|c|c|}
\hline & \multicolumn{4}{|c|}{ Drug } & \multirow[b]{2}{*}{ Potency ratio } \\
\hline & RTI 3 I & RTI 5 I & WIN 35428 & Cocaine & \\
\hline In vivo DAT binding ( $\mu \mathrm{mol} / \mathrm{kg} / \mathrm{rat})$ & $0.08(0.02-0.2)$ & $0.08(0.02-0.2)$ & $0.39(0.16-0.9)$ & $8.8^{\#}(7.75-10.0)$ & $1: 1: 5: 110$ \\
\hline In vitro DAT binding $(\mathrm{nM})$ & $1.96(1.49-1.58)$ & $1.55(0.9-2.6)$ & $29(24-35)$ & $265(213-328)$ & $1: 0.8: 15: 135$ \\
\hline
\end{tabular}

$N=5$ or 4 (RTI 5 I) for self-administration by rhesus monkeys under a PR schedule; $n=3$ for in vivo DAT binding in rats; and $n=3$ in vitro DAT binding in rhesus monkey brain. Self-administration data and in vivo binding data are $\mathrm{ED}_{50}$ doses $\left( \pm \mathrm{SEM}\right.$ or $95 \% \mathrm{Cl}$, respectively). In vitro binding data are $K_{\mathrm{i}}$ concentrations $(95 \% \mathrm{Cl}$ ). \#Data have previously been published (Woolverton et al, 2002)

$0.025 \mathrm{mg} / \mathrm{kg} / \mathrm{session}$ of RTI 31 when 0.0015 and $0.0003 \mathrm{mg} /$ $\mathrm{kg}$ /injection of RTI 31 were made available, while monkey 96R0661 self-administered 0.028 and $0.023 \mathrm{mg} / \mathrm{kg} / \mathrm{session}$ at these doses.

Although there was some initial self-administration of $0.0015 \mathrm{mg} / \mathrm{kg} /$ injection of RTI 31 by $97 \mathrm{R} 0111$ and $96 \mathrm{R} 0679$, stable self-administration above saline levels was not maintained in these monkeys (Figure 3). When the dose of RTI 31 was increased to $0.01 \mathrm{mg} / \mathrm{kg} /$ injection, stable self-administration was maintained above saline level with an average of 5.7 (97R0111) or 7.7 (96R0679) injections/ session. When $0.0015 \mathrm{mg} / \mathrm{kg} /$ injection was again made available, self-administration of 36.3 (97R0111) and 42
(96R0679) injections/session was maintained. In monkey 97R0111, the number of injections/session increased further to an average of 117 as the dose of RTI 31 was further decreased to $0.0003 \mathrm{mg} / \mathrm{kg} /$ injection, but the number of injections/session was not maintained in monkey 96R0679. As with the other two monkeys, the total intake of reinforcing doses of RTI 31 were similar across the doses (ie 97R0111: $0.057 \mathrm{mg} / \mathrm{kg} / \mathrm{session}$ at $0.01 \mathrm{mg} / \mathrm{kg} /$ injection and $0.055 \mathrm{mg} / \mathrm{kg} / \mathrm{session}$ at $0.0015 \mathrm{mg} / \mathrm{kg} /$ injection; 96R0679: $0.077 \mathrm{mg} / \mathrm{kg} / \mathrm{session}$ at $0.01 \mathrm{mg} / \mathrm{kg} /$ injection and $0.063 \mathrm{mg} /$ $\mathrm{kg} / \mathrm{session}$ at $0.0015 \mathrm{mg} / \mathrm{kg} /$ injection). When saline was available at the end of the study, the number of injections decreased to the initial saline level in all monkeys (Figure 3). 


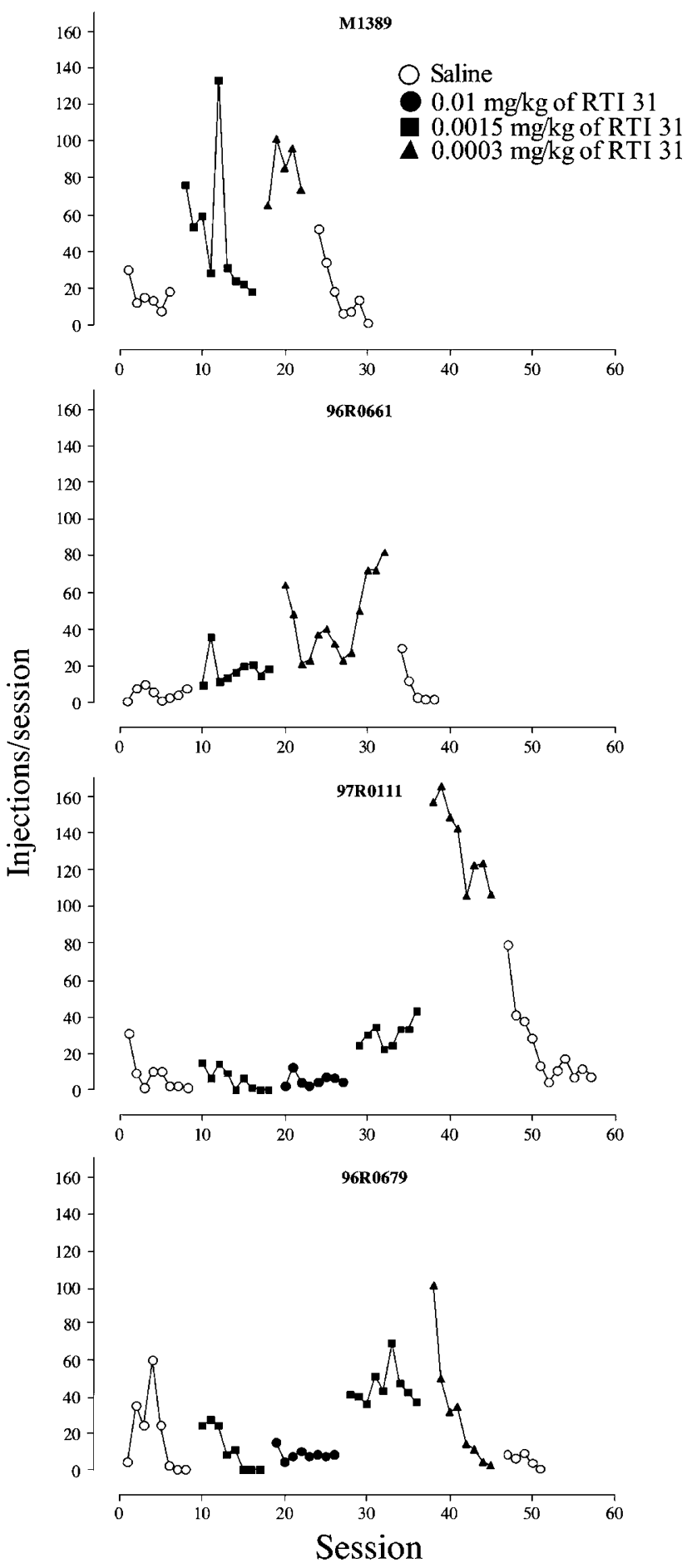

Figure 3 Self-administration of RTI 3 I by individual monkeys under a FR I schedule of reinforcement. Abscissa: consecutive sessions; ordinate: injections/session. Sessions were $4 \mathrm{~h}$ long.

\section{In Vivo Binding}

The striatum/cerebellum ratio of in vivo $\left[{ }^{3} \mathrm{H}\right.$ ]WIN 35428 binding was approximately 5.8. All the compounds displaced $\left[{ }^{3} \mathrm{H}\right.$ ]WIN 35428 binding in rat striatum in a dose-dependent manner (Figure 4). The order of potency was RTI $31=$ RTI $51>$ WIN $35428>$ cocaine (Table 1 ).
When compared to cocaine, RTI 31 and RTI 51 were approximately 100 -fold more potent, whereas WIN 35428 was about 23 -fold more potent than cocaine.

In the kinetic experiments, cocaine displaced radioligand binding within $2 \mathrm{~min}$ of the injection (Figure 5a). WIN 35428, RTI 31, and RTI 51, on the other hand, took between 20 min (WIN 35428) and 30 min (RTI 51) after the injection to decrease radioligand binding. All the compounds displaced the $\left[{ }^{3} \mathrm{H}\right]$ WIN 35428 binding between 38 and $51 \%$ at maximum. The slopes of the best fit lines for $\left[{ }^{3} \mathrm{H}\right]$ WIN 35428 displacement were $0.017,0.012,0.0074$, and 0.0077 for cocaine, WIN 35428, RTI 31, and RTI 51, respectively (Figure $5 \mathrm{~b}$ ). The estimated $T_{25}$ 's were $5.8,22.3$, 30.7 , and $44.1 \mathrm{~min}$ for cocaine, WIN 35428 , RTI 31 , and RTI 51 , respectively. The $T_{50}$ 's were $14.3,34.7,50.4$, and $63.1 \mathrm{~min}$ for cocaine, WIN 35428, RTI 31, and RTI 51, respectively. There was a significant difference among the slopes for $\left[{ }^{3} \mathrm{H}\right]$ WIN 35428 displacement. Specifically, pairwise post hoc comparisons revealed that the slope for cocaine significantly differed from all the others, whereas no other differences were statistically significant.

\section{In Vitro Binding}

Cocaine and the cocaine analogs displaced the binding of all the radioligands at monoamine transporters in a concentration-dependent manner (data not shown). The data for all the compounds were fit best to a one-site model for all three transporters. The order of DAT affinity was RTI $31=$ RTI $51>$ WIN $35428>$ cocaine (Table 2). RTI 31, RTI 51, and WIN 35428 were, respectively, about 133-, 133- and nine-fold more potent than cocaine at the DAT, 15-, 123-, and three-fold at the NET, and 13-, 64- and 1.3-fold at the 5-HTT. The affinity ratios of the compounds at the 5-HTT relative to the DAT differed within an order of magnitude across the compounds. On the other hand, the affinity ratios of the compounds at the NET relative to the DAT varied within a range of 5-82.

\section{Relationship between Reinforcing Effects, Pharmacokinetics, and Pharmacodynamics}

The potency relationship among the drugs for in vivo DAT binding was significantly correlated with potency as a reinforcer $\left(r^{2}=0.99, p=0.004\right)$. The correlation between in vitro binding affinity at the DAT and potency as a reinforcer also achieved statistical significance $\left(r^{2}=0.98, p=0.009\right)$. Binding affinities of the drugs at the DAT in vivo were correlated with those in vitro $\left(r^{2}=0.94, p=0.03\right)$. Potency as a reinforcer was not correlated with any other measure of in vitro binding at monoamine transporters including binding affinities at the NET, 5-HTT, NET/DAT, or 5HTT/DAT.

The maximum number of injections under the PR schedule was significantly correlated with the postinjection time of $T_{25}$ and $T_{50}$ in in vivo DAT binding (Figure 6) and with the slopes of the linear regression lines for in vivo DAT binding (Figure $5 \mathrm{~b} ; r^{2}=0.95, p=0.03$ ). With regard to in vitro binding affinities at monoamine transporters, the maximum number of injections was not correlated with any of binding affinities at the NET, 5-HTT, 5-HTT/DAT, or NET/DAT. Interestingly, the negative correlation between 


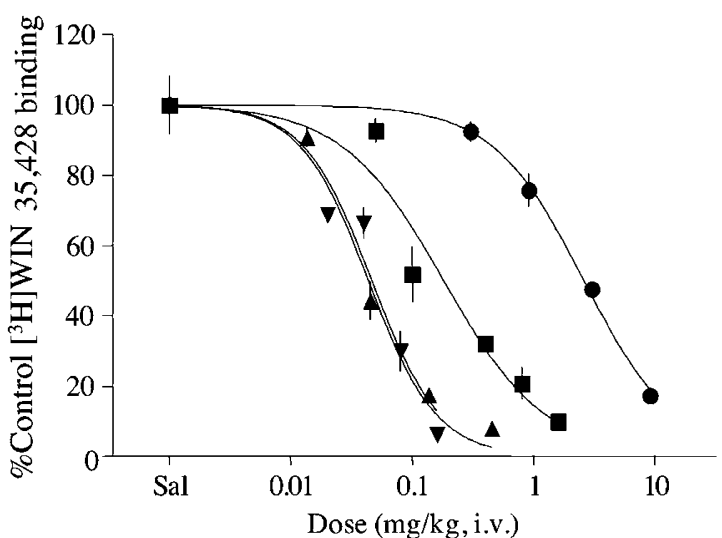

\begin{tabular}{|c|}
\hline ED $_{50}$ doses \\
Cocaine $=2.68 \mathrm{mg} / \mathrm{kg}(8.8 \mu \mathrm{mol} / \mathrm{kg})$ \\
WIN $35,428=0.17 \mathrm{mg} / \mathrm{kg}(0.39 \mu \mathrm{mol} / \mathrm{kg})$ \\
$\boldsymbol{\nabla}$ RTI $31=0.04 \mathrm{mg} / \mathrm{kg}(0.08 \mu \mathrm{mol} / \mathrm{kg})$ \\
RTI $51=0.04 \mathrm{mg} / \mathrm{kg}(0.08 \mu \mathrm{mol} / \mathrm{kg})$
\end{tabular}

Figure 4 Dose-response function of in vivo DAT binding of cocaine, WIN 35428, RTI 3I, and RTI $5 \mathrm{I}$ as a function of dose in rats $(n=3)$. Cocaine data were redrawn from Woolverton et al (2002). Data of $\left[{ }^{3} \mathrm{H}\right] \mathrm{WIN} 35428$ binding ratio at striatum/cerebellum were transformed to the percent of those after saline treatment. Various doses of a drug were injected first, then $\left[{ }^{3} \mathrm{H}\right] \mathrm{W}$ IN 35428 was injected. All the rats were killed 45 min after $\left[{ }^{3} \mathrm{H}\right] \mathrm{WIN} 35428$ injection.

the maximum number of injections and binding affinities at the DAT in vitro and between the maximum number of injections and binding affinities at the DAT in vivo was found significant $\left(r^{2}=0.97, p=0.02 ; r^{2}=0.96, p=0.02\right)$.

\section{DISCUSSION}

As has been reported for DAT ligands (Bergman et al, 1989; Ritz et al, 1987), cocaine, WIN 35428, RTI 31, and RTI 51 functioned as positive reinforcers. WIN 35428 has been previously found to function as a positive reinforcer in squirrel monkeys and rats responding under a second-order and a fixed-ratio schedule, respectively (Spealman et al, 1991; Norman et al, 2004, respectively). Self-administration of RTI 31 and RTI 51 has not been reported previously. The significant correlation between DAT binding affinity and potency as a reinforcer further supports the notion that

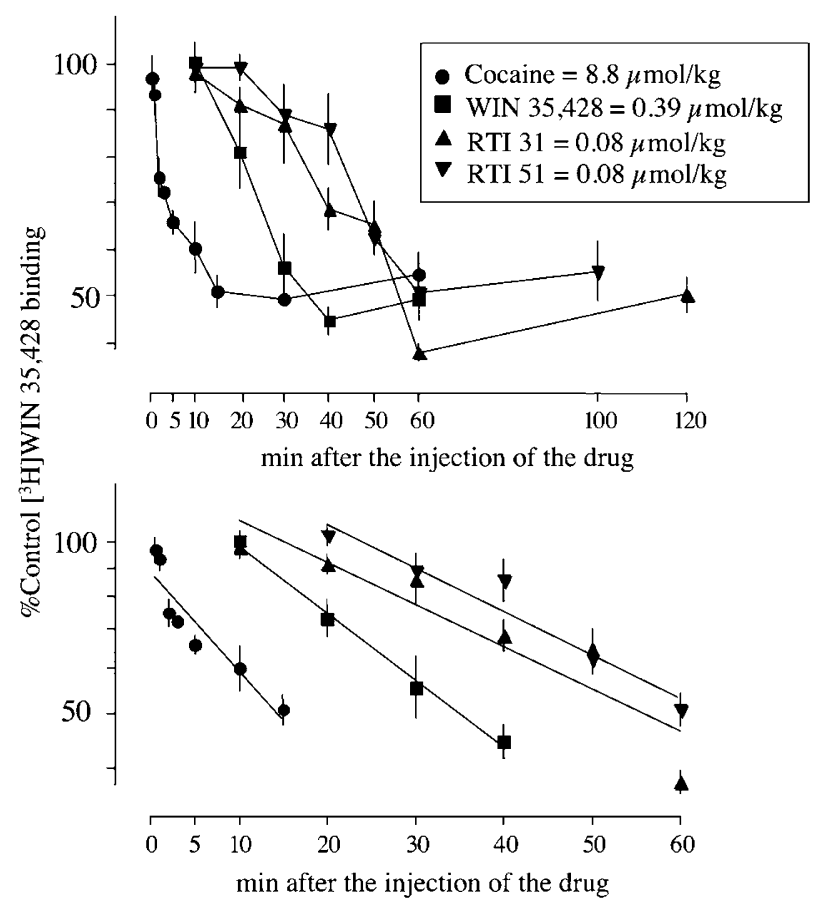

Figure 5 (a) In vivo DAT binding of $\mathrm{ED}_{50}$ doses of cocaine, WIN 35428 , RTI 3I, and RTI $5 \mid$ as a function of time in rats $(n=3-6)$. Cocaine data were redrawn from Woolverton et al (2002). $\left[{ }^{3} \mathrm{H}\right] \mathrm{WIN} 35428$ was first injected to occupy the DAT and the $\mathrm{ED}_{50}$ doses of the drugs were injected $45 \mathrm{~min}$ after $\left[{ }^{3} \mathrm{H}\right] \mathrm{WIN} 35428$ injection. Rats were killed at indicated time points after the $\mathrm{ED}_{50}$ doses of the drugs were injected. (b) In vivo DAT binding of the cocaine and analogs. A linear regression line was obtained for each drug from the latest time point when the $\left[\mathrm{H}^{3}\right]$ WIN 35428 binding was not reduced below $100 \%$ of the control binding (ie mean + SEM $\geqslant 100$ ) to the time point of the maximum displacement. The ordinate is in log scale.

action at the DAT contributes to the reinforcing effect of cocaine-like compounds (see Wise, 1978; Woolverton and Johnson, 1992). Besides the reinforcing effect, cocaine-like discriminative stimulus effects have been reported for WIN 35428 and RTI 31 in pigeons and rats, respectively (Jarbe, 1981; Balster et al, 1991). The potency relationship between cocaine and RTI 31 as discriminative stimuli was comparable to the relationship as positive reinforcers, that is, approximately 30 -fold, implying the involvement of DA in the discriminative stimulus effect of cocaine and RTI 31 (Balster et al, 1991). All of the tested compounds have also

Table 2 Inhibition of Radioligand Binding to Monoamine Transporters in Rhesus Monkey Brain Tissues

$$
K_{\mathrm{i}}(\mathrm{nM})
$$

\section{$\left[{ }^{3}\right.$ H]WIN 35428}

\section{RTI 5 I}

RTI 31

WIN 35428

Cocaine

$1.55(0.9-2.6)$
$1.96(1.49-1.58)$
$29(24-35)$
$265(213-328)$

$265(213-328)$ $\left[{ }^{3} \mathrm{H}\right]$ Nisoxetine

||$(7.2-16.7)$
$|6|(105-247)$
$49 \mid(315-765)$
$24 \mid(512-3009)$

$124 \mid(512-3009)$ $\left[{ }^{3} \mathrm{H}\right]$ Paroxetine

$3.3(1.9-5.8)$
$4.55(3.2-6.4)$
$153(87-269)$
$192(138-265)$

Ratio (DAT : NET : SERT)

Data are the mean and $95 \% \mathrm{Cl}$ (within parentheses) of three experiments $(n=3)$, each in duplicate determinations. The caudate/putamen was used for the dopamine transporter binding; the cerebellum, for the norepinephrine transporter binding; and the frontal cortex, for the serotonin transporter binding.

Neuropsychopharmacology 


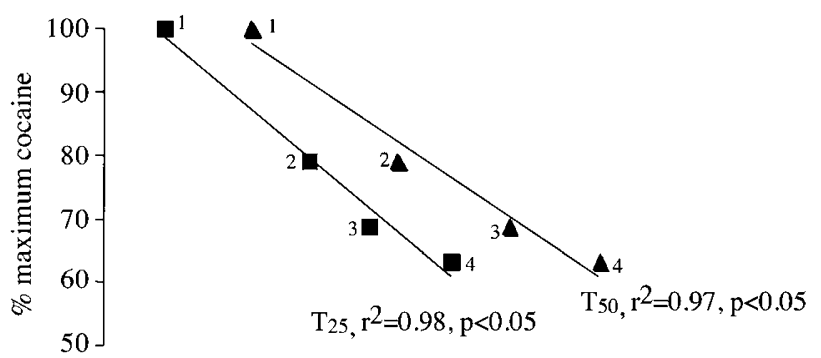

$\begin{array}{llllllll}0 & 10 & 20 & 30 & 40 & 50 & 60 & 70\end{array}$

Time to decrease binding (minutes)

Figure 6 Correlation between the maximum self-administration by rhesus monkeys under a PR schedule and binding onsets at the DAT in rats. $T_{25}$ and $T_{50}$ represent the postinjection time when a drug displaced 25 and $50 \%$ of control $\left[{ }^{3} \mathrm{H}\right]$ WIN 35428 binding, respectively, in in vivo binding assays. I, Cocaine; 2, WIN 35428; 3, RTI 3I; and 4, RTI 5 I.

been shown to increase locomotor activity in rats or mice (de Saint Hilaire et al, 1995; Kimmel et al, 2001; Tolliver and Carney, 1995). Together, these results suggest that these cocaine analogs would have psychostimulant-like abuse potential.

By progressively increasing response requirement, a PR schedule measures the maximum amount of behavior that a subject emits for a reinforcer, thereby allowing a quantitative estimate of the reinforcing strength or efficacy (see Depoortere et al, 1993; Stafford et al, 1998). When measured under the present PR schedule, the order of the maximum number of injections was cocaine $>$ WIN 35428>RTI $31 \geqslant$ RTI 51. Taking into account a fast onset of cocaine in the CNS, slower onset of WIN 35428, RTI 31, and RTI 51 were hypothesized to contribute to their diminished reinforcing efficacy relative to cocaine. In the in vivo DAT binding experiments in rats, onset of DAT binding obtained as $T_{25}$ or $T_{50}$ was in the order of cocaine $>$ WIN $35428>$ RTI $31>$ RTI 51, comparable to the order of reinforcing efficacy of cocaine $>$ WIN $35428>$ RTI $31 \geqslant$ RTI 51 . Rate of binding was, moreover, negatively correlated with reinforcing efficacy, supporting the hypothesis. Onset of in vivo DAT binding includes various pharmacokinetic factors including distribution to the CNS and association rate with the DAT. The slopes of linear regression lines for in vivo DAT binding may represent rate of DAT binding at the site of action. The significantly steeper slope for cocaine than those for the cocaine analogs in in vivo DAT binding suggested a faster binding rate of cocaine at the DAT than that of the cocaine analogs. A faster association rate of cocaine with the DAT than that of WIN 35428 has previously been suggested in that the equipotent concentrations of $\left[{ }^{3} \mathrm{H}\right]$ cocaine and $\left[{ }^{3} \mathrm{H}\right]$ WIN 35428 achieved the equilibrium binding at the DAT in vitro in 20 and $90 \mathrm{~min}$, respectively (Madras et al, 1989a, b).

Under the present PR schedule, all the drugs maintained responding with biphasic dose-response functions. Although a 1-h time out between trials and $30 \mathrm{~min}$ of a limited hold for an injection was used to minimize a drug accumulation, the descending limbs suggest that drug accumulation over a session at the highest doses disrupted ongoing responding, thereby influencing the maximum number of injections at those doses. Spealman et al (1977) reported that doses of cocaine and WIN 35428 in the range of those tested herein could disrupt ongoing schedulecontrolled responding in squirrel monkeys. Similar results were described with cocaine and WIN 35428 in rats responding for food presentation (D'Mello et al, 1981). The in vivo binding data, in fact, suggest that these cocaine analogs have long duration of action at the DAT relative to cocaine, consistent with previous reports (Spealman et al, 1977; Kimmel et al, 2001). Biphasic dose-response functions are common in drug self-administration, even with short-acting drugs and when long TO periods programmed after injections (Griffiths et al, 1979; Panlilio and Schindler, 2000; Risner and Goldberg, 1983). The mechanism for these nonspecific effects has not been clearly established, and may include motor disruptions, satiation, or aversive effects of high doses. That dose-response functions were parallel over the full range of doses argue against the conclusion that these effects differentially influenced estimates of relative reinforcing effect of the drugs under the present PR condition. Nevertheless, the present results should be considered with the caveat that drug accumulation may have influenced the maximum number of injections.

The order of onset of in vivo DAT binding in the present experiment was different from the previous report qdescribing the order of onset of DAT binding as cocaine $>$ RTI $51>$ RTI $31=$ WIN 35428, in mice (Stathis et al, 1995). Although the exact reason(s) is not clear, different $\mathrm{ED}_{50}$ doses were used in the two studies, perhaps leading to different conclusions. The $\mathrm{ED}_{50}$ 's of RTI 51, RTI 31, and cocaine were higher in Stathis et al's (1995) study than in the present study by two to four times, while the values of WIN 35428 were similar. In the present study, to determine $\mathrm{ED}_{50}$ 's, we established optimal pretreatment time between each test drug and $\left[{ }^{3} \mathrm{H}\right]$ WIN 35428 injection (ie 3-10 $\mathrm{min}$ ) to allow enough time for a test drug to bind at the DAT. In the Stathis et al (1995) study, however, a standard 5-min pretreatment time was used for all drugs. The fact that the pretreatment time for WIN 35428 in the present study was $5 \mathrm{~min}$ and the $\mathrm{ED}_{50}$ value was comparable to that in Stathis et al's study (1995) supports this conclusion.

Previous research raised the possibility of a positive relationship between DAT affinity and efficacy as a reinforcer. For instance, local anesthetics with weaker affinities at the DAT maintained lower break points than cocaine under a PR schedule (Wilcox et al, 2000; Woolverton, 1995). Similarly, a piperidine cocaine analog, which has slightly weaker affinity at the DAT than cocaine, was a weaker reinforcer than cocaine (Woolverton et al, 2002). However, when a correlation between efficacy as a reinforcer and potency at the DAT was made among seven monoamine transporter inhibitors, no relationship was found (Lile et al, 2003). Interestingly, the present study found a negative relationship between binding affinities at the DAT in vivo and reinforcing efficacy and between binding affinities at the DAT in vitro and reinforcing efficacy. Thus, the relationship between potency at the DAT and efficacy as a reinforcer among DAT ligands remains equivocal. 
The self-administration of the cocaine analogs achieved at relatively high response requirements under the $P R$ schedule may be surprising considering the slow onset of binding, particularly for RTI 31 and RTI 51. It is possible that the extensive histories of these monkeys in the selfadministration of cocaine and other stimulants influenced the self-administration of these compounds. Nader and Mach (1996) reported that 7-OH-DPAT, a D3 DA receptor agonist, reliably maintained self-administration in drugexperienced monkeys but failed to do so in drug-naïve monkeys. It has been proposed that similar discriminative stimulus effects between a baseline drug and a test drug may contribute to an increased likelihood of self-administration of the test drug (Young and Woods, 1981). The observation that naïve monkeys acquired dose-responsive self-administration of RTI 31 suggests that the reinforcing effect of RTI 31 under the PR schedule was not determined by previous history of stimulant self-administration. This demonstration that a slow-onset drug such as RTI 31 established and maintained self-administration in naïve monkeys is consistent with the suggestion that although slow-onset kinetics can reduce reinforcing efficacy, there may be a limit to this effect (Woolverton and Wang, 2004). The observations that various classes of abused drugs can function as positive reinforcers via the oral route, where onset is relatively slow, provides support for this conclusion (see review Meisch, 2001).

Besides onset of action, pharmacodynamic actions may influence reinforcing efficacy. Serotonergic activity of stimulants has been proposed to influence relative reinforcing efficacy of compounds with mixed monoamine actions (Roberts et al, 1999; Wee et al, 2005). It, however, seems unlikely that differences in the serotonergic activity of the drugs in the present study contributed to the differences in relative reinforcing efficacy observed under the PR schedule. In an in vitro binding assay using monkey brain tissue, we found that the affinity ratios of 5-HTT/DAT were within an order of magnitude across compounds. Further, the relative potency of the drugs at the 5-HTT/DAT or at the 5HTT alone was not related to reinforcing efficacy of the compounds.

Cocaine binds at sodium channels, dopamine, muscarinic, and sigma receptors in addition to monoamine transporters (see reviews Ritz and George, 1997; Matsumoto et al, 2003; Smith et al, 2004). Among those sites, the interaction with muscarinic receptors and sigma receptors were found to be related to the toxicity, seizure, or lethality of cocaine (Matsumoto et al, 2004; Ritz and George, 1993). Interaction with the sodium channels was also implicated to work against the reinforcing effect of local anesthetics (Wilcox et al, 1999). The potencies of WIN 35428, RTI 31, and RTI 51 at sodium channels and muscarinic and sigma receptors were not determined in the present study. In another study, WIN 35428 was reported to have five- to six-fold higher potency in binding at muscarinic M1 and M2 receptors and similar affinity at sigma receptors to that of cocaine (Ritz and George, 1993). Thus, considering the structural similarity, the cocaine analogs may have good affinities at those sites. Wilcox et al (2000) suggested that the 'therapeutic index' or the ratio between reinforcing dose and toxic/adverse dose determines reinforcing efficacy of drugs. Therefore, the likely increased affinities of the cocaine analogs at muscarinic or sigma receptors might have narrowed their 'therapeutic indices', thereby limiting the maximum self-administration of the drugs, particularly at high doses, but it is still speculative.

Taken together, the present data strengthen the conclusion that a slower onset or rate of DAT binding is associated with diminished efficacy as a reinforcer among DAT ligands. Our findings also support the conclusion that although onset of action is a determinant of reinforcing efficacy, there may be limits to this effect. Drugs with quite slow onsets of action can function as efficacious reinforcers.

\section{ACKNOWLEDGEMENTS}

We gratefully acknowledge the expert advice of Dr Warren May on the statistical analysis and the excellent technical assistance of Hamilton McGee in the self-administration study. We also thank Zhixia Wang for conducting the in vitro binding experiment with RTI 31 . This study was supported by National Institute on Drug Abuse Grants DA-10352 (to WLW) and DA-05477 (to FIC). WLW is the recipient of NIDA Grant K05-DA15343.

\section{REFERENCES}

Balster RL, Carroll FI, Graham JH, Mansbach RS, Rahman MA, Philip A et al (1991). Potent substituted-3 beta-phenyltropane analogs of cocaine have cocaine-like discriminative stimulus effects. Drug Alcohol Depend 29: 145-151.

Balster RL, Schuster CR (1973). Fixed-interval schedule of cocaine reinforcement: effect of dose and infusion duration. J Exp Anal Behav 20: 119-129.

Bergman J, Madras BK, Johnson SE, Spealman RD (1989). Effects of cocaine and related drugs in nonhuman primates. III. Selfadministration by squirrel monkeys. J Pharmacol Exp Ther 251: 150-155.

Brady JV, Griffiths RR (1976). Behavioral procedures for evaluating the relative abuse potential of CNS drugs in primates. Fed Proc 35: 2245-2253.

Carroll FI, Gao Y, Rahman MA, Abraham P, Parham K, Lewin AH et al (1991). Synthesis, ligand binding, QSAR and CoMFA study of $3 \beta$-(p-substituted phenyl)tropane- $2 \beta$-carboxylic acid methyl esters. J Med Chem 34: 2719-2725.

Cheng YC, Prusoff WH (1973). Relationship between the inhibition constant (Ki) and the concentration of inhibitors which causes 50 percent inhibition $\left(I_{50}\right)$ of an enzyme reaction. Biochem Pharmacol 22: 3099-3108.

D'Mello GD, Goldberg DM, Goldberg SR, Stolerman IP (1981). Conditioned taste aversion and operant behavior in rats: effects of cocaine, apomorphine and some long-acting derivatives. $J$ Pharmacol Exp Ther 219: 60-68.

de Saint Hilaire Z, Python A, Blanc G, Charnay Y, Gaillard JM (1995). Effects of WIN 35428 a potent antagonist of dopamine transporter on sleep and locomotor activity in rats. Neuroreport 6: $2182-2186$.

Depoortere RY, Li DH, Lane JD, Emmett-Oglesby MW (1993). Parameters of self-administration of cocaine in rats under a progressive-ratio schedule. Pharmacol Biochem Behav 45: 539-548.

Fowler JS, Volkow ND, Logan J, Gatley SJ, Pappas N, King P et al (1998). Measuring dopamine transporter occupancy by cocaine in vivo: radiotracer considerations. Synapse 28: 111-116. 
Griffiths RR, Bradford LD, Brady JV (1979). Progressive ratio and fixed ratio schedules of cocaine-maintained responding in baboons. Psychopharmacology 65: 125-136.

Jarbe TUC (1981). Cocaine cue in pigeons: Time course studies and generalization to structurally related compounds (norcocaine, WIN 35428 and 35065-2) and (+)-amphetamine. Br J Pharmacol 73: 843-852.

Kaufman MJ, Madras BK (1992). Distribution of cocaine recognition sites in monkey brain: II. Ex vivo autoradiography with $\left[{ }^{3} \mathrm{H}\right] \mathrm{CFT}$ and $\left[{ }^{125} \mathrm{I}\right] \mathrm{RTI}-55$. Synapse 12: 99-111.

Kimmel HL, Carroll FI, Kuhar MJ (2001). Locomotor stimulant effects of novel phenyltropanes in the mouse. Drug Alcohol Depend 65: 25-36.

Lile JA, Morgan D, Birmingham AM, Wang Z, Woolverton WL, Davies HML et al (2002). The reinforcing efficacy of the dopamine reuptake inhibitor $2 \beta$-propanoyl-3 $\beta$-(4-tolyl)-tropane (PTT) as measured by a progressive ratio schedule and a choice procedure in rhesus monkeys. J Pharmacol Exp Ther 303: 640-648.

Lile JA, Wang Z, Woolverton WL, France JE, Gregg TC, Davies HM et al (2003). The reinforcing efficacy of psychostimulants in rhesus monkeys: The role of pharmacokinetics and pharmacodynamics. J Pharmacol Exp Ther 307: 356-366.

Madras BK, Fahey MA, Bergman J, Canfield DR, Spealman RD (1989b). Effects of cocaine and related drugs in nonhuman primates. I. $\left[{ }^{3} \mathrm{H}\right]$ Cocaine binding sites in caudate-putamen. J Pharmacol Exp Ther 251: 131-141.

Madras BK, Spealman RD, Fahey MA, Neumeyer JL, Saha JK, Milius RA (1989a). Cocaine receptors labeled by $\left[{ }^{3} \mathrm{H}\right] 2$ betacarbomethoxy-3 beta-(4-fluorophenyl)tropane. Mol Pharmacol 36: $518-524$.

Matsumoto RR, Gilmore DL, Pouw B, Bowen WD, Williams W, Kausar A et al (2004). Novel analogs of the sigma receptor ligand BD1008 attenuate cocaine-induced toxicity in mice. Eur J Pharmacol 492: 21-26.

Matsumoto RR, Liu Y, Lerner M, Howard EW, Brackett DJ (2003). Sigma receptors: potential medications development target for anti-cocaine agents. Eur J Pharmacol 469: 1-12.

Meisch RA (2001). Oral drug self-administration: an overview of laboratory animal studies. Alcohol 24: 117-128.

Nader MA, Mach RH (1996). Self-administration of the dopamine $\mathrm{D}_{3}$ agonist 7-OH-DPAT in rhesus monkeys is modified by prior cocaine exposure. Psychopharmacology 125: $13-22$.

Norman AB, Buesing WR, Norman MK, Tabet MR, Tsibulsky VL (2004). The self-administration of WIN 35, 428 and cocaine: comparisons of satiety threshold and elimination half-life in rats. Eur J Pharmacol 483: 281-287.

Panlilio LV, Goldberg SR, Gilman JP, Jufer R, Cone EJ, Schindler CW (1998). Effects of delivery rate and non-contingent infusion of cocaine on cocaine self-administration in rhesus monkeys. Psychopharmacology 137: 253-258.

Panlilio LV, Schindler CW (2000). Self-administration of remifentanil, an ultra-short acting opioid, under continuous and progressive-ratio schedules of reinforcement in rats. Psychopharmacology 150: 61-66.

Risner ME, Goldberg SR (1983). A comparison of nicotine and cocaine self-administration in the dog: fixed-ratio and progressive-ratio schedules of intravenous drug infusion. J Pharmacol Exp Ther 224: 319-326.

Ritz MC, George FR (1993). Cocaine-induced seizures and lethality appear to be associated with distinct central nervous system binding sites. J Pharmacol Exp Ther 264: 1333-1343.

Ritz MC, George FR (1997). Cocaine toxicity: concurrent influence of dopaminergic muscarinic and sigma receptors in mediating cocaine-induced lethality. Psychopharmacology 129: $311-321$
Ritz MC, Lamb RJ, Goldberg SR, Kuhar MJ (1987). Cocaine receptors on dopamine transporters are related to self-administration of cocaine. Science 237: 1219-1223.

Roberts DC, Phelan R, Hodges LM, Hodges MM, Bennett B, Childers $S$ et al (1999). Self-administration of cocaine analogs by rats. Psychopharmacology 144: 389-397.

Rowlett JK, Massey BW, Kleven MS, Woolverton WL (1996). Parametric analysis of cocaine self-administration under a progressive-ratio schedule in rhesus monkeys. Psychopharmacology 125: 361-370.

Scheffel U, Pogun S, Stathis M, Boja JW, Kuhar MJ (1991). In vivo labeling of cocaine binding sites on dopamine tran sporters with $\left[{ }^{3} \mathrm{H}\right] \mathrm{WIN}$ 35428. J Pharmacol Exp Ther 257: 954-958.

Smith JE, Co C, Yin X, Sizemore GM, Liguori A, Johnson III WE et al (2004). Involvement of cholinergic neuronal systems in intravenous cocaine self-administration. Neurosci Biobehav Rev 27: $841-850$

Spealman RD, Bergman J, Madras BK (1991). Self-administration of the high-affinity cocaine analog 2 beta-carbomethoxy-3 beta-(4-fluorophenyl)tropane. Pharmacol Biochem Behav 39: 1011-1013.

Spealman RD, Goldberg SR, Kelleher RT, Goldberg DM, Charlton JP (1977). Some effects of cocaine and two cocaine analogs on schedule-controlled behavior of squirrel monkeys. J Pharmacol Exp Ther 202: 500-509.

Stafford D, LeSage MG, Glowa JR (1998). Progressive-ratio schedules of drug delivery in the analysis of drug selfadministration: a review. Psychopharmacology 139: 169-184.

Stathis M, Scheffel U, Lever SZ, Boja JW, Carroll FI, Kuhar MJ (1995). Rate of binding of various inhibitors at the dopamine transporter in vivo. Psychopharmacology 119: 376-384.

Tella SR, Ladenheim B, Cadet JL (1997). Differential regulation of dopamine transporter after chronic self-administration of bupropion and nomifensine. J Pharmacol Exp Ther 281: 508-513.

Tolliver BK, Carney JM (1995). Locomotor stimulant effects of cocaine and novel cocaine analogs in DBA/2J and C57BL/6J inbred mice. Pharmacol Biochem Behav 50: 163-169.

Volkow ND, Wang GJ, Fischman MW, Foltin R, Fowler JS, Franceschi D et al (2000). Effects of route of administration on cocaine induced dopamine transporter blockade in the human brain. Life Sci 67: 1507-1515.

Wee S, Anderson KG, Bauman M, Rothman R, Woolverton WL (2005). Relationship between the serotonergic activity and reinforcing effects of a series of amphetamine analogs. J Pharmacol Exp Ther 313: 1-7.

Wee S, Ordway GA, Woolverton WL (2004). Reinforcing effect of pseudoephedrine isomers and the mechanism of action. Eur J Pharmacol 493: 117-125.

Wilcox KM, Paul IA, Woolverton WL (1999). Comparison between dopamine transporter affinity and self-administration potency of local anesthetics in rhesus monkeys. Eur J Pharmacol 367: $175-181$

Wilcox KM, Rowlett JK, Paul IA, Ordway GA, Woolverton WL (2000). On the relationship between the dopamine transporter and the reinforcing effects of local anesthetics in rhesus monkeys: practical and theoretical concerns. Psychopharmacology 153: 139-147.

Wise RA (1978). Catecholamine theories of reward: a critical review. Brain Res 152: 215-247.

Woolverton WL (1995). Comparison of the reinforcing efficacy of cocaine and procaine in rhesus monkeys responding under a progressive-ratio schedule. Psychopharmacology 120: 296-302.

Woolverton WL, Hecht GS, Agoston GE, Katz JL, Newman AH (2001). Further studies of the reinforcing effects of benztropine analogs in rhesus monkeys. Psychopharmacology 154: 375-382. 
Woolverton WL, Johnson KM (1992). Neurobiology of cocaine abuse. Trends Pharmacol Sci 13: 193-200.

Woolverton WL, Ranaldi R, Wang Z, Ordway GA, Paul IA, Petukhov $\mathrm{P}$ et al (2002). Reinforcing strength of a novel dopamine transporter ligand: pharmacodynamic and pharmacokinetic mechanisms. J Pharmacol Exp Ther 303: 211-217.
Woolverton WL, Wang Z (2004). Relationship between injection duration, transporter occupancy and reinforcing strength of cocaine. Eur J Pharmacol 486: 251-257.

Young AM, Woods JH (1981). Maintenance of behavior by ketamine and related compounds in rhesus monkeys with different self-administration histories. J Pharmacol Exp Ther 218: $720-727$. 